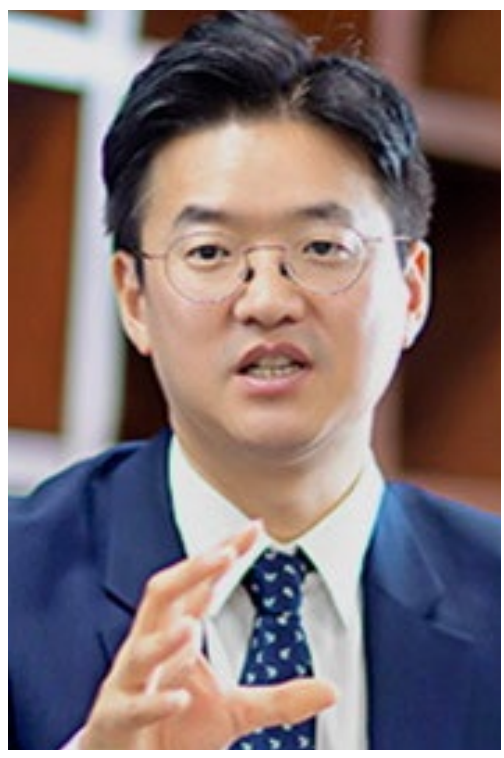

\title{
Entrevista
}

Jung-won Park,

latinoamericanista del

Center for Cross-Cultural

Studies de Corea del Sur

\section{LA PANDEMIA CUESTIONA LA HEGEMONÍA OCCIDENTAL Y PERMITE PENSAR UN MUNDO "POST-HUMANO"}

Por Soonbae Kim

DOI: https://doi.org/10.51188/rrts.num24.483

Obtuvo su doctorado en Lengua y Literaturas Hispánicas en la Universidad de Pittsburgh, EUA. Su área de investigación incluye la literatura y el cine latinoamericano, los estudios fronterizos y los estudios transpacíficos entre Asia y América Latina. Sus ensayos han sido publicados en México, Estados Unidos, Reino Unido, Argentina, Ecuador y Corea. Fue profesor de la Universidad de Colorado del Norte. Actualmente es profesor del departamento de español y director del Center for Cross-Cultural Studies en la Universidad Kyung Hee, Corea del Sur.

Presentamos una entrevista realizada en noviembre de 2020, que tomó como base un cuestionario preparado por el equipo editor de Revista Rumbos TS.

1 Doctor en Ciencias Sociales, Universidad de Chile. Magíster en Estudios de Área Internacional (mención en Ciencias Políticas), Hankuk University of Foreign Studies, Corea del Sur. Director del Magíster en Estudios Coreanos de la Universidad Central de Chile y del Centro de Estudios Comparados de Corea de la misma universidad. Dirección postal: Lord Cochrane 417, Santiago CP: 8330507, Chile.

Email: soonbae.kim@ucentral.cl 


\section{-Para comenzar, ¿podría contarnos en qué consiste su trabajo académico? ¿Cuáles han sido sus principales temas de interés?}

-Primeramente, me gustaría expresar mi gran agradecimiento por invitarme a este diálogo transpacífico. Mi campo de trabajo consiste básicamente en la literatura latinoamericana y los estudios culturales. Después de terminar mi maestría en Corea, fui a Estados Unidos para seguir mis estudios. Obtuve mi doctorado en la Universidad de Pittsburgh con una tesis sobre los fenómenos culturales de la frontera entre México y Estados Unidos con énfasis en los temas de migración, violencia e identidad cultural. Luego, por cinco años, trabajé en la Universidad de Colorado del Norte enseñando literatura y cultura latinoamericanas, estudios latinxs y de las fronteras del mundo, etc.

Mi estancia de diez años en Estados Unidos, sobre todo, me abrió las puertas para pensar y repensar mis propios objetivos de estudiar e investigar para convertirme en un latinoamericanista coreano. Siempre me han preguntado por qué motivo quise estudiar América Latina, así como sobre la relación entre Corea y América Latina o sobre las ventajas y desventajas de ser coreano al estudiar América Latina. Estas preguntas me han empujado a seguir mis investigaciones sobre América Latina en un enfoque comparativo con Corea y Asia en general. En este sentido, mi tesis doctoral es de alguna manera un ejemplo de esa relación, ya que la frontera mexicano-estadounidense me fascinó como el máximo símbolo de la globalización, mientras que mi país vive todavia en la frontera anacrónica trazada por los protagonistas de la Guerra Fría.

Después de volver a Corea hace siete años, he buscado temas que puedan tender puentes entre Corea y América Latina. Por un lado, empiezo a desarrollar el proyecto de análisis comparativo de las narrativas literarias y cinematográficas de la postdictadura, tanto en Corea como en los países del Cono Sur. Por otro lado, desde la perspectiva de la "antípoda", pretendo reivindicar las experiencias transpacíficas marcadas por la migración, el viaje y otros encuentros en el siglo XX y el siglo XXI. Recientemente hice una reseña, publicada en la Revista Asia/América Latina, sobre el libro En Corea del Norte: viaje a la última dinastía comunista, de Florencia Grieco, periodista argentina.

\section{AMÉRICA LATINA Y COREA: EL IMAGINARIO DEL FRACASO Y EL ÉXITO DE LA MODERNIZACIÓN}

\section{-¿Cuáles son las percepciones comunes de la gente de su país sobre América Latina?}

-La percepción general sobre América Latina en Corea es bastante influenciada por los medios norteamericanos, así que no es muy diferente de las imágenes estereotipadas. Los coreanos no pueden diferenciar un país de América Latina de otro. Para ellos, todo es una entidad homogénea llamada América Latina, desde el Río Bravo hasta Tierra del Fuego. No obstante, hay un par de puntos interesantes para recalcar en cuanto a la imagen de América Latina en Corea. 
Por un lado, para la gente coreana América Latina en general está sufriendo de la pobreza, la desigualdad y, sobre todo, la violencia. Esta percepción les permite a los coreanos pensar que América Latina es modelo de fracaso en el proceso de la modernización, contrastando el caso de Corea que se ha destacado como uno de los ejemplos más exitosos, saliendo del país más pobre del mundo en menos del medio siglo y siendo el ideal para los países en vía de desarrollo. En esta línea, para los coreanos América Latina se convierte en un "oceano azul" en donde se puede desarrollar el comercio bilateral, la inversión financiera y la ayuda extranjera como socio de negocio.

Por otro lado, los coreanos saben más o menos de las experiencias históricas de América Latina: la colonización, la independencia, la intervención política y económica de los países poderosos, la dictadura y la democratización. Y quieren sentirse cercanos e incluso identificados con los latinoamericanos, porque tienen, asimismo, experiencias de la colonización de las primeras décadas del siglo XX y de la intervención política de los Estados Unidos después de la guerra civil. Así, creen compartir una historia similar con América Latina. Para los ojos coreanos, los latinoamericanos, a pesar de tales dificultades y sufrimientos, son gente feliz y afectiva. Lo que admiran los coreanos, entonces, es que los latinoamericanos saben, supuestamente, disfrutar de la vida y seguir adelante, pese a las adversidades. Cantar, bailar y festejarse en su cultura son cosas entendidas como maneras de atravesar las dificultades y vivir la vida entera.

\section{-Y en su país en particular, ¿cómo están los estudios de América Latina y cuáles son las principales áreas de interés y estudio?}

-En Corea, los estudios de América Latina fueron generados en los departamentos de lengua española de las universidades. Por esta razón, al principio fueron reducidos al campo de la literatura. Luego, poco a poco aparecieron personas que habían estudiado español, originalmente, y después obtuvieron títulos de maestría o doctorado en otras áreas; de este modo, los estudios latinoamericanistas en Corea se extendieron a la sociología, la historia, la antropología, las ciencias políticas, las relaciones internacionales y la economía.

Ahora tenemos una organización de latinoamericanistas llamada Latin American Studies Association of Korea (LASAK) que incluye a cerca de 150 miembros de varios campos de estudio. Esta asociación, que ya tiene más de 20 años de historia, organiza congresos anuales y realiza actividades académicas varias. Además de eso, los centros de estudios latinoamericanos de algunas universidades reciben fondos financieros del Estado y están llevando a cabo investigaciones enfocadas en temas de desigualdad, ambientalismo y desarrollo sustentable, así como negocios internacionales con América Latina.

Pese a que no hay muchos latinoamericanistas en cada área de estudio, nos hemos extendido a varias disciplinas y ahora incluimos temas muy diversos. La academia coreana intenta, efectivamente, introducir las nuevas tendencias de los estudios realizados en América Latina y en otros países. Últimamente, por ejemplo, nos ha interesado mucho el movimiento ecologista y sus implicaciones para el "buen vivir", 
al igual que los intentos de poner en práctica la idea del post-desarrollo y de las leyes de protección de la naturaleza, en el sentido de que, en Corea, seguimos inmersos en la ilusión del desarrollismo y no hemos prestado suficiente atención al cambio climático y a la destrucción de los ecosistemas. Así, se están publicando ensayos académicos y libros traducidos desde varias perspectivas sobre estos temas.

\section{ES NECESARIO UN DIÁLOGO DIRECTO E “INTERPERIFÉRICO”, SIN MEDIACIÓN DEL CENTRO, ENTRE ASIA Y AMÉRICA LATINA}

\section{-Según su opinión, ¿̇cuáles son los principales desafíos para los estudios sobre Asia y América Latina en ciencias sociales y humanidades?}

-Si bien la globalización ha precitipado el contacto y los encuentros entre Asia y América Latina, todavía sentimos la distancia geográfica, cultural y psicológica. Pero esto no es un obstáculo sino más bien una precondición. Lo más importante es que, debido a tales distancias, los estudios entre Asia y América Latina dependen en gran medida de las miradas del centro. A nosotros llegan las noticias y la información generadas en los países hegemónicos como los de Europa y Estados Unidos. De este modo es difícil realizar el diálogo directo e interperiférico, sin mediación del centro, entre las dos partes.

A este respecto, debería mencionarse también la falta de comunidad intelectual entre Asia y América Latina. Hay poco espacio académico para conversar acerca de nuestros intereses y nuestras preocupaciones. Cada uno hace sus cosas sin que la otra parte las conozca. Por eso nos cuesta encontrar los recursos y desarrollar una discusión profunda.

Finalmente, no hemos hallado hasta ahora un "lenguaje común" en el campo de los estudios entre Asia y América Latina. De hecho, los términos "América Latina" y "Asia” no van más allá de la significación geográfica. Requerimos una teoría a través de la cual se pueda justificar la necesidad de involucrar a las dos regiones juntas. Desde hace poco nos hemos apropiado del concepto del "Sur global", con miras a deconstruir la hegemonía de los países poderosos y apoyar los diálogos y la solidadridad entre los países periféricos. Sin embargo, este concepto está todavía por definirse, rellenarse de significados y reflexionarse. Existen, en el Sur global, discrepancias, cacofonías y desigualdades, así que nuestra pregunta sería cómo construir una plataforma conjunta basada en las diferencias radicales en y entre las dos regiones. 
-Debido al desarrollo de las TIC (Tecnologías de la Información y la Comunicación) y nuevas plataformas como YouTube, las culturas asiáticas llegan y se consumen cada vez más en América Latina. En su opinión, ¿qué efectos están generando estos cambios en la comprensión bilateral entre los pueblos de ambos continentes?

- Hace cinco años tuve la oportunidad de visitar Cuba. Me sorprendí cuando una adolescente cubana se me acercó saludando y mostrando un video de una telenovela coreana en YouTube y me dijo que era fanática de un actor coreano. No me gusta exagerar, pero esta experiencia fue un verdadero shock para mí.

Hay que admitir que la "ola" coreana - K-pop, K-drama, K-beauty — todavía es un fenómeno cultural, en su mayor parte, solo entre las generaciones jóvenes. Sin embargo, es sin duda también una nueva forma en la que tiene lugar el diálogo bilateral y el compartir entre las culturas sin la filtración de los medios de mainstream del centro. En YouTube, no es difícil ver muchos comentarios en español en los videos musicales de BTS. En cierto modo, los jóvenes están creando un "nuevo lenguaje" para comunicarse cruzando fronteras de nación, raza, idioma y cultura.

De hecho, en los años 90 hubo el fenómeno de la salsa y del latin dance en Corea. En la colonia universitaria de la capital, aparecieron, en aquella época, varias salsotecas en donde los jóvenes coreanos (iincluyéndome a mí!) aprendían español, conocían la comida latina y, en general, se familiarizaban con la cultura latinoamericana. Se puede regresar aún más en el tiempo, de hecho. En las décadas de los 70 y de los 80 , la teoría de la dependencia fue un referente indispensable para los jóvenes militantes y los intelectuales que querían comprender mejor la política neocolonial de la península coreana. No nos damos cuenta, pero los intercambios culturales existieron y siguen.

En este sentido, la "ola" coreana en América Latina no es una invasión de la cultura asiática. Más bien puede ser entendida como una nueva etapa de la comunicación bilateral dentro del contexto transpacífico. Nos falta, eso sí, espacios y recursos para investigar esto. Nuestra tarea, entonces, consiste en examinar este flujo cultural y establecer centros e instituciones en los que se pueda realizar y extender estudios sostenibles entre y sobre América Latina y Asia. 


\section{EL ANTROPOCENO Y UN MUNDO "POST-HUMANO"}

-La Pandemia es otra instancia que invita a repensar el orden global centrado en Europa y Estados Unidos hasta ahora. ¿Qué rol podrán jugar Asia y América Latina, que hasta ahora de cierta manera han estado más marginados que Europa y Estados Unidos, en el nuevo orden global y cómo afectará la convivencia de la humanidad a futuro?

-Sabemos que ahora todo el mundo está sufriendo del COVID-19. Pero esta pandemia no solamente muestra el poder abrumador del virus, sino que también revela muchos problemas ocultados en nuestras sociedades. Lo que sentimos los coreanos en medio de la pandemia es que ya no hay hito o paradigma con el que podamos seguir y caminar. Antes podíamos aceptar la hegemonía de "Occidente" y seguir el orden mundial encabezado por él. Pero parece que Europa y Estados Unidos no saben qué hacer con esta pandemia. Más bien, lo que estamos observando es una situación desastrosa y caótica en esos países. Así, nos preguntamos: ¿dónde están la democracia y el consenso social de los que se jactaban Europa y Estados Unidos? ¿Pueden ser esos países, reducidos a la irracionalidad y el fracaso en tiempos de pandemia, ejemplos que podríamos querer seguir como modelos ideales para resolver nuestros problemas?

Esperamos, por supuesto, superar esta pandemia y regresar a la vida "normal" pronto. El actual orden mundial va a durar más, pero es obvio que no puede garantizar un futuro sostenible. $Y$ nuestra pregunta es: ¿cómo reconstruir una "nueva normalidad" en la que participen también los países anteriormente no hegemónicos y marginados, así como establecer consensos sociales más inclusivos y democráticos? En este sentido, el papel de Asia y de América Latina es importante. La globalización ha consolidado el poder de los países occidentales y, ante la pandemia, la globalización cede a nuevas formas de nacionalismo para esos mismos países. Salen noticias, por ejemplo, de que ya casi están listas las vacunas contra el coronavirus, pero a la vez nos enteramos de que estas van a ser inmediatamente compradas y usadas por los países ricos. América Latina y Asia deben trabajar juntos para elevar sus voces, equilibrar el balance del poder y crear nuevas formas de comunidad global que estén imbuidas de los valores menospreciados y de las perspectivas ignoradas en el actual orden mundial. 


\begin{abstract}
-Sin hablar de la pandemia actual, la humanidad ahora enfrenta distintos desafíos como violación de derechos humanos, migraciones, igualdad de género, cambio climático, la cuarta revolución industrial, por dar algunos ejemplos. ¿Cómo Asia y América Latina, cruzando las fronteras y el pacífico, podrán trabajar juntos frente a estos desafíos comunes en esta era de gran transición?
\end{abstract}

-Estoy de acuerdo: estamos pasando por una era de transición. Durante las últimas dos décadas, América Latina ha ocupado un lugar emblemático en este proceso transicional. En cierta forma, allí compiten los tres proyectos existentes: (1) la globalización neoliberal (como el proyecto de la derecha), (2) las modernizaciones alternativas (proyectos izquierdistas al nivel del Estado) y (3) la creación de mundos post-capitalistas y post-liberalistas. En Asia, el camino de China entra en el juego de debate: ¿es un nuevo tipo del poder que quiere simplemente reemplazar la posición de Estados Unidos? ¿O tomará otro camino alternativo, yendo más allá de la modernidad occidental?

Este panorama nos permite hacer una reflexión crítica sobre las tendencias emergentes. Al hablar de la transición, me gustaría sugerir el antropoceno como un marco teórico para explicar nuestra época de crisis. Este concepto proviene de una conciencia escéptica y, hasta cierto punto, apocalítica: el cambio climático y la destrucción de los ecosistemas ha sido causado por los seres humanos y por su antropocentrismo. Para detener esta crisis, urge colaborar internacionalmente, independientemente del lugar de origen de los problemas concretos, porque las consecuencias son globales y porque se trata de una responsabilidad compartida entre todos los seres humanos.

Al mismo tiempo, no debemos olvidar el punto ciego en la teoría del antropoceno. En la tradición occidental, el ser humano, como especie, ha sido representado por el "hombre blanco" que ocupa un lugar privilegiado ante las mujeres, las poblaciones de color, los animales y las plantas. En esta línea, los países europeos y Estados Unidos son responsables, en el mundo moderno, del grueso de la destrucción del medio ambiente, mientras que Asia y América Latina son regiones "víctimas" que han sido objeto de procesos de desarrollo, explotación y colonialismo en beneficio del centro.

En este sentido, Asia y América Latina se sitúan como testigos que evidencian el antropocentrismo, así como que pueden hacer un reposicionamiento de la noción del ser humano hacia una con la cual se pueda buscar una convivencia con los otros seres de este planeta. Este planteamiento de un sujeto "post-humano" también nos posiblita reflexionar este tema conjuntamente con los de la cuarta revolución industrial y la inteligencia artificial. 


\title{
"QUEREMOS OTRO TIPO DE MUNDO, NO NECESARIAMENTE DIRIGIDO POR LOS MECANISMOS DE LA CIVILIZACIÓN MODERNA Y OCCIDENTAL"
}

\author{
-Mirando el futuro ¿qué temas considera fundamentales para estimular \\ los vínculos entre las academias de ambos continentes?
}

-Aunque estamos, de momento, encerrados en cada país debido a la pandemia, lo que ha transformado nuestra vida durante las últimas tres décadas es la globalización asociada con la política neoliberal. Este fenómeno ha diluido las fronteras nacionales, posibilitando los movimientos de mercancías, información, cultura y seres humanos. Sin embargo, con su agudización, la globalización también, acaso inesperadamente, ha causado o intensificado problemas como la discriminación, el racismo, la desigualdad y la violencia. A mi modo de ver, no hemos hallado una salida para escaparnos de estos problemas.

No obstante, gracias a la globalización nos damos cuenta también de que todo el mundo está vinculado e interrelacionado de manera compleja, de tal forma que, para resolver problemas, se requiere colaboraciones de varias regiones y muchos países. En otras palabras, sentir la urgencia de sembrar solidaridad transnacional se convierte en una de las tareas más significativas de nuestro tiempo. Así, podemos y necesitamos empezar a trabajar juntos con un énfasis en los estudios comparativos.

En este sentido, América Latina y Asia comparten los asuntos de la migración, la nueva pobreza y la desigualdad social, por no hablar del medio amibiente. Cada caso es diferente y particular, por supuesto, pero sería útil pensar siempre estos y otros temas dentro del contexto transnacional. Esto nos llevará a poder precisar la idea del "Sur global" y a estudiar estos temas desde la perspectiva periférica del mundo, sin depender de las miradas de Europa y Estados Unidos.

\footnotetext{
-Para terminar, usted es director del Center for Cross-Cultural Studies. En el contexto de sus respuestas anteriores, desde la perspectiva del Centro, ¿qué busca específicamente en estudios sobre América Latina? Considerando la visión del Centro de construir una nueva comunidad que persiga valores alternativos de vida, desde una diversidad cultural y una felicidad sostenible.
}

-La visión de nuestro centro de investigación -buscar un mundo o una comunidad alternativa- suena ingenua y soñadora, tomando en cuenta que estamos viviendo un tiempo muy difícil e incluso distópico. Pero, por la mismia razón, opinamos que soñar, imaginar y diseñar se vuelve importante en este momento. Corea del Sur ha crecido mucho económicamente y ahora está entre los diez primeros países del planeta en cuanto al tamaño de su comercio internacional. Sin embargo, la gente se siente infeliz y estresada, y esta sensación es particularmente aguda entre los jóvenes. La expresión Hell Joseon ${ }^{2}$, uno de los neologismos acuñados por la generación joven, simboliza su frustración, rabia y depresión. Por supuesto, Corea

2 La frase mezcla las palabras "Infierno" y "Joseon” (la última dinastía de Corea). 
del Sur pertenece a los países con los porcentajes más altos de suicidio en el mundo. Entonces, nuestras preocupaciones son, en última instancia, cómo entender esta situación, por qué la gente se siente infeliz en la prosperidad económica y, finalmente, cómo solucionar este problema.

En este contexto, valdría la pena mirar hacia afuera para repensar nuestras condiciones de vida y buscar otros modos de pensar, de vivir y de relacionarnos entre personas y como humanidad con la naturaleza. América Latina, en particular, ha sido conocido como un verdadero laboratorio de ideologías a lo largo del siglo XX (por no hablar de sus sabidurías ancestrales), por lo que podemos ver una inmensa diversidad de formas, de ideas y de prácticas concebidas a través de civilizaciones, historias y tradiciones muy ricas que desembocan en movimientos emergentes en esta época de globalización. Por ejemplo, el concepto de "pluriverso", elaborado por autores decoloniales como Walter Mignolo y Arturo Escobar, nos llama mucha la atención, en el sentido de que, también en Corea, queremos ver otro tipo de mundo no necesariamente dirigido por los mecanismos de la civilización moderna y occidental que los coreanos hemos, acríticamente, seguido y copiado como modelo perfecto e ideal.

Nuestro centro de investigación trabaja para crear espacios en los que se pueda dar un diálogo más directo con las voces latinoamericanas, sin pasar por las miradas del centro. Queremos compartir las experiencias de cada parte, buscar similitudes y celebrar diferencias, así como encontrar un mejor futuro que no esté controlado por la lógica del capital. En este sentido, nuestro centro intenta siempre desempeñar el rol de puente entre Asia y América Latina. 